\title{
Beyond the Google Generation: towards community-specific usage patterns of scientific information
}

\author{
Chérifa Boukacem-Zeghmouri \\ Joachim Schöpfel
}

\begin{abstract}
This chapter questions the concept of the Google Generation commonly used to explain information behaviour. The authors try to understand the impact of disciplines on the information behaviour of researchers in science, technology and medicine. A review and analysis of usage studies and empirical results are reported from a qualitative survey with scientists from different disciplines (biology, physics, mathematics, geology and chemistry). Thirty interviews set the information behaviour - information research, reading behaviour, scientific communication and publishing in the wider framework of scientific activity. Specific attention is paid to new models of academic publishing (open access). Ethnographic observations allow for a reinterpretation of discourse and practice in the information users' work space.
\end{abstract}

Keywords: attitude, Google generation, information behaviour, researchers, usage patterns

\section{Generation gap and community}

Today, researchers can access a wide range of subscription, pay-per-view or open-access digital resources. When invited to evaluate this offer, their answer is unanimous. They wish to be able to access 'more of these resources, at all times and from anywhere'. What do we know about their behaviours and attitudes?

While access to digital scientific information steadily increases, a growing body of empirical studies provides evidence on usage patterns by academic scholars, scientists and students. They usually focus either on information-seeking behaviour as a radical new phenomenon or try to establish a continuum with the 'Gutenberg galaxy' and former research (Tenopir et al., 2009). One of the main questions relates to information literacy and a generation gap between 'digital natives' and 'digital immigrants' (Prensky, 2001). The digital natives or Google generation [1] are defined as 'those born after 1993 ... a cohort of young people with little or no recollection of life before the Web' (Rowlands et al., 2008). A couple of studies strived to confirm the stereotype of this Google generation and to show typical and specific information behaviour performed by those who have 'grown up in a world dominated by the Internet' (Rowlands et al., 2008).

Some examples of real or alleged Google generation behaviour patterns (see OCLC, 2006; Rowlands et al., 2008) include: '89\% of college students use search engines to begin an information search ... They prefer visual information over text ... They prefer interactive systems and are turning away from being passive consumers of information ... They think everything is on the web (and it's all free) ...' (Rowlands et al., 2008) and so on. The question about the reality and reliability of these generational patterns is not theoretical but practical because of its impact on teaching programmes, didactics, educational engineering and infrastructure. [2]

Students and younger researchers have also been described as digital natives and as 'Google 
academics', for example bloggers and tweeters, familiar with social networks and collaborative tools, doing most of their information research online. On the other hand, older scientists are less acquainted with the Internet, unimpressed by Google and more reluctant to engage with information and communications technology (ICT). But does the concept of the Google generation explain the total variation of scholarly information behaviour?

One of the first to express reservations was Schulmeister (2008). In a well-documented working paper, he argued for a functional and educational approach to the Internet generation, focusing on socialisation processes, not on media. A recent research project conducted by Education for Change [3] casts doubt on the application of the Google generation concept to research communities. Tomorrow's researchers seem not so very different from researchers today.

We think that the Google generation is a transitional phenomenon and that the research environment or ecosystem, covering the whole spectrum from project team and institution to research community and scientific discipline, and including career and other strategic choices, may have a more structuring impact than age or generation.

This chapter questions the concept of the Google generation commonly used to explain information behaviour. Instead, we try to understand better the impact of disciplines on the information behaviour of researchers in science, technology and medicine (STM). We do not deny possible behavioural convergences and similarities between researchers from different disciplines but we highlight the structuring effect of their specific disciplinary environment, status and social representations of identified practices. Our proposal is to review recent studies on information behaviour in academic environments, to adopt a differential approach and highlight behavioural differences across the range of scientific disciplines. [4]

We then report empirical results from a qualitative survey with scientists from five disciplines (biology, physics, mathematics, geology and chemistry). Thirty interviews set the information behaviour - information research, reading behaviour, scientific communication and publishing - in the wider framework of scientific activity. Specific attention is paid to new models of academic publishing, such as open access. Ethnographic observations allow for a reinterpretation of discourse and practice in the information users' work space. The aim is to change the perspective, go beyond the Google generation concept and focus on the community as an ecosystem.

\section{Disciplines and subjects in usage studies}

Some studies aggregate findings about information behaviour, without taking into account differences across the demographic characteristics of the respondents. Tenopir et al. (2004) observed how undergraduates, graduates and faculty members performed sessions on ScienceDirect. [5] 
They distinguished three disciplines (astronomy/physics, chemistry and engineering) but neglected this variable in their interpretation of the results. King et al. (2009) report on a survey with faculty from five United States universities with detailed evidence on information-seeking and reading patterns - as if all scholars behave the same way. Yet the authors are conscious that 'differences in reading patterns result most often from differences in academic disciplines, followed by readers' primary duties (teaching or research), their productivity (faculty who publish more, read more), and their age (older faculty are more likely to read print and to have more personal subscriptions)' (King et al., 2009).

A recent review of literature mentions that 'there were disciplinary differences in methods or use [and] in the use of literature from fields other than searchers' own core interests' (Williams et al., 2010) but then comes to the conclusion that keyword searching in e-journals became the common information behaviour shared by all disciplines. Yet, two studies have focused on the differences in academic disciplines. The 2006 Research Information Network (RIN) report on researchers' usage of discovery services is one of the first studies to apply a disciplinary approach to usage studies. Even though the report states that '[the] similarities are more striking than the differences', it confirms community- specific usage patterns of online services such as library portals and search engines in life sciences, physical sciences, arts and humanities, and social sciences. A follow-up report on the use, value and impact of e-journals (RIN, 2009a) affirms that 'readers in different subjects behave differently' and shows differences in information behaviour related to disciplines. 'E-journal databases ... do not appear to force users into a common style of behaviour. Subjects do!' (RIN, 2009a; see also Nicholas et al., 2010).

A JISC study on e-books provides complementary empirical evidence (JISC, 2009). Students' information behaviour is evaluated by means of deep log analysis of course text e-books in four academic disciplines. In particular, seasonal patterns, access location (sessions off/on campus), page view times and session lengths differ significantly between the four subsamples. Centre for Information Behaviour and the Evaluation of Research (CIBER) publications introduced discipline-related usage patterns from 2005 onwards. Two studies on usage data from Blackwell (Nicholas et al., 2005) and the OHIOLink consortium (Nicholas et al., 2007) revealed some subject-related differences, especially with regard to the number of sessions and article views and to the format of requested items. The 2008 article on Elsevier's ScienceDirect platform provides a 'detailed and comprehensive subject profile of users' that is meant to improve e-journal systems to become more suitable for users in different disciplines (Nicholas et al., 2008). Some results were as follows:

Social Scientists conducted ... the highest proportion ... of sessions viewing only abstracts [and] conducted the highest proportion ... of sessions which viewed only articles in press ... Over a quarter of the sessions conducted by Mathematicians included a view to old articles ... Physicists were the most likely to view their own journals $-71 \%$ of the journals viewed by them were Physics journals. Computer scientists were the most regular visitors to 
ScienceDirect. (Nicholas et al., 2008).

After a comprehensive review of log analyses on subject-related usage patterns, Nicholas et al. (2009) compared usage data from history, economics and life sciences collections (Oxford University Press) and concluded that 'subject and institutional differences ... were sometimes considerable, a finding which points to the danger of generalising about usage and information seeking.' A recent study allows for deeper insight into the discipline-related impact on information-seeking behaviour insofar as it draws attention to narrower subject communities within scientific disciplines (Jamali and Nicholas, 2008a, 2008b, 2010). Based on qualitative survey data, the authors describe similarities but also significant differences in methods of finding and using research articles between seven academic sub-fields of astronomy and physics. The findings somehow confirm but then, too, go beyond former results: '... as we can see, different subfields are different and talking of physicists here might be over-generalising the data' (Jamali and Nicholas, 2008a). Table 1 gives an overview on eight research projects. The table shows the surveyed disciplines and sub-disciplines, and indicates whether the disciplines were surveyed as characteristics of the community (= the faculty's research field) or of the requested items (= subject of collections, journals or ebooks).

What can be learned from these studies (reference numbers in table 1)?

1. The research reviewed covers the whole range of fields of science, including natural sciences, formal sciences, social sciences and applied sciences, with the exception of cognitive sciences. Nevertheless, this coverage is not consistent, and only the publications based on Jamali's PhD thesis (2008a, 2010) take into account subdivisions and interdisciplinary disciplines (5).

2. Four studies $(2,4,5$ and 8$)$ define disciplines through scientific communities, by the research interests and affiliations of academic users (students, scholars). Four other studies (1, 3, 6 and 7) define disciplines through the subject of requested content (collections), as if the theme of an article, journal or e-book was necessarily and always related to the discipline of the user. In all cases, disciplines and/or subjects have not been labelled by the authors/scientists but adopted from the publishers, libraries, institutions or users that were surveyed, weakening coherence and comparability between the different studies.

3. The hypothesis of statistically significant differences of information- seeking behaviour related to academic disciplines seems consistent throughout all studies and apparently does not depend on the choice of research methods (survey, deep log analysis, library usage data, item analysis).

4. The observed differences affect several aspects of information-seeking behaviour, such as format, age or status of requested items, number of sessions, visits, searches or retrieved hits, or attitudes to services and tools.

5. Nevertheless, the results provide more or less anecdotal evidence, for example a 
patchwork-like description rather than consistent data on information-seeking behaviour in different scientific communities. In other words, it is not possible, at least for the moment, to draw a consistent picture of specific heuristic patterns related to digital information in history, economics, chemistry or other communities.

Table 1 Review of academic disciplines in usage studies

\begin{tabular}{|r|r|r|r|r|l|l|l|l|}
\hline & 1 & 2 & 3 & 4 & 5 & 6 & 7 & 8 \\
\hline Community (user) & & $\mathrm{x}$ & & $\mathrm{x}$ & $\mathrm{x}$ & & & $\mathrm{x}$ \\
\hline Collection (content) & $\mathrm{x}$ & & $\mathrm{x}$ & & & $\mathrm{x}$ & $\mathrm{x}$ & \\
\hline Science & $\mathrm{x}$ & & $\mathrm{x}$ & & & & & \\
\hline Chemistry & & & & $\mathrm{x}$ & & & & $\mathrm{x}$ \\
\hline Materials science & & & & $\mathrm{x}$ & & & & \\
\hline Physics & & $\mathrm{x}$ & & $\mathrm{x}$ & $\mathrm{x}$ & & & $\mathrm{x}$ \\
\hline Astronomy & & & & & $\mathrm{x}$ & & & \\
\hline Mathematics & & & & $\mathrm{x}$ & & & & \\
\hline Earth sciences & & & & $\mathrm{x}$ & & & & $\mathrm{x}$ \\
\hline Environmental sciences & & & & $\mathrm{x}$ & & & & $\mathrm{x}$ \\
\hline Life sciences & & $\mathrm{x}$ & & $\mathrm{x}$ & & $\mathrm{x}$ & & $\mathrm{x}$ \\
\hline Medicine & $\mathrm{x}$ & & $\mathrm{x}$ & $\mathrm{x}$ & & & $\mathrm{x}$ & \\
\hline Social sciences & $\mathrm{x}$ & $\mathrm{x}$ & $\mathrm{x}$ & $\mathrm{x}$ & & & & \\
\hline Media studies & & & & & & & $\mathrm{x}$ & \\
\hline Arts \& humanities & $\mathrm{x}$ & $\mathrm{x}$ & $\mathrm{x}$ & & & & & \\
\hline History & & & & & & $\mathrm{x}$ & & $\mathrm{x}$ \\
\hline Engineering & & & $\mathrm{x}$ & $\mathrm{x}$ & & & $\mathrm{x}$ & \\
\hline management & & & & & & & $\mathrm{x}$ & \\
\hline
\end{tabular}

1. Nicholas et al. (2005)

4. Nicholas et al. (2008)

6. Nicholas et al. (2009)
2. RIN (2006)

5. Jamali and Nicholas (2008, 2010)

7. JISC (2009)
3. Nicholas et al. (2007)

8. RIN (2009a) Nicholas et al. (2010)

Following the studies, a couple of factors impact or moderate discipline-related differences, such as length of experience, academic status of the user group surveyed and type of research conducted, and the research output of institutions in terms of activity and intensity, especially between teaching and research universities. And we can probably add strategic positioning of the researcher and competition within the research environment as systemic variables that interconnect community, discipline and personality (Kurek et al., 2007). We can summarise with a recent JISC-OCLC report on user behaviour projects (Connaway and Dickey, 2010): 'Several studies indicate that some disciplinary differences do exist in researcher behaviours, both professional researchers and students', even if the increasing 
centrality and integrating effect of e-journals and Google or similar search engines in researchers' behaviour should not be underestimated.

\section{The Google generation concept and French STM researchers}

We were offered the opportunity to study French researchers' digital practices and behaviour in the STM fields during a four-year (2006-10) national research project. [6] The combination of methodologies used (qualitative and quantitative) gave us a more complete picture of the manner in which the French academic community appropriated electronic resources and to what degree. The qualitative part of the study provided in-depth understanding of the disciplinary dynamics underlying the practices recorded in the logs. Our challenge was to reconstruct the 'intelligence' of the quantitative part so as to make explicit the meaning and therefore better understand behaviour and usage. The interview structure placed the user's information-seeking behaviour within the discipline's scientific activity. It raised questions relating to the sociology of science and information and communication sciences. The goal was to reconstruct the 'continuum' of scientific activity within each discipline so as to contextualise better behaviour and usage. This methodological approach allowed us to observe closely researchers' everyday way of work. Consequently, we were able to determine whether or not the practices observed were related to the 'Google generation' concept. The researchers we interviewed were members of laboratories from five universities: Paris 6, Lyon 1, Lille 1, Strasbourg 1 and Bordeaux 1.

\section{Cultural differences between fields}

The results of our analysis highlight the fundamental importance of social representations in the researcher's practices and usage. Frequently underestimated, or even ignored, this dimension is clearly visible in the interviews we conducted with 30 scholars from five disciplines: biology, physics, mathematics, geology and chemistry. The methodological approach gave us a broad and dynamic view of the researcher's daily work methods, certainly helping to bring this to light. By social representations, we mean 'social knowledge between individuals and groups' (Le Marec, 2001) that is consensual within a discipline and adhered to by researchers. This 'referential reality' was found in both the interviews and in the practices we observed in situ (workspace organisation, consultation of editor platforms, consultation of bibliometric databases). During the interviews, social representations were oriented around two spheres. The first was the researcher's perception of his individuality, his place within a larger entity - most often the laboratory. The second was his perception of his community and his place within it.

For the physicists and theoretical mathematicians that we interviewed and observed, the feeling of being an integral part of the community is explained by the community being seen as a place for sharing, discussing, learning and experimenting. The community is capable of stimulating the fundamental nature of research in these fields. It promotes both the sharing of content (articles, data) and technical skills related to the systems used to produce the content. The community is therefore seen as providing the researcher with everything 
necessary to 'stay in the race': tools to access the latest research (ArXiv) [7] and the latest open and interoperable systems and software. The community appears to be a place where one goes for information and training. The researchers interviewed considered themselves to be integral to this dynamic.

The need to be in constant contact with the community is linked with the need to be aware of the most recent research. These two aspects are self-determined. Consequently, through alerts, spontaneous consultations, word of mouth and online navigation, the researcher is in a state of constant awareness. The feeling of proximity to and integration in the community is reinforced by the fact that the researcher considers it to be a space where research can evolve to the paper stage, in the pre-print sense of the word. The community, through systems such as open archives, enables the researcher to complete the research and scientific communication processes. All the stages are present: reflection, communication, comments and review (first evaluation stage). This explains why repositories, ArXiv in particular, are as important as academic journals. Scientific publications are important for a researcher's career but are not part of the continuum found in the community. This explains the scattered aspect of their informational practices during the scientific communication process. Their screens display the multiple interfaces they use to search for the elements that will allow them to retrace a research path. In addition, their screens also display various word processing programs and other software. They are therefore connected to the Web and multi-tasking out of necessity. They are constantly logged into e-mail which they use to send messages (a question, a request for more information) to the members of their community whether they know them or not. The most remarkable fact was that the institutional membership had no impact on this representation. Claiming to be a big, international, scientific family, institutional considerations are secondary. The status of a researcher, however, was a significant factor in determining 'expert' profiles.

Researchers with the most research experience and responsibilities have practices that are closest to those of the Google generation. In particular, those researchers with important review activities (articles, projects, PhD student advisees) - often the oldest - and who use search engines the most, have practices that most resemble those of the Google generation. The search engine is seen as a harvester meant to 'reconstruct the research environment': PDFs with bibliographic references, home pages of cited authors and so on. The age criterion associated with the Google generation disappears when confronted with the status and nature of review activity. Researchers' informational practices, objective and observable phenomena, are shaped upstream and are based on the idea the researcher makes of his or her choice of action. Multi-tasking, a constant presence on the Web, shared learning experiences, digital forms of communication, the community as a substitute for official authority figures - all are symptoms of a functionality deeply embedded in the social practices of the field. They are exacerbated and revealed on the Web. They cannot, however, be considered as new phenomena. 
Among the biologists, chemists and geologists we encountered, proximity with the community is found on two levels: national and international. This dual representation exists because researchers primarily collaborate on the first, more limited, level and frequently publish on the second, broader, level. This dual representation goes hand in hand with a feeling of distance: the experimental nature of research requires the researcher to regularly break with his or her community (small or large). The researcher is isolated when working in the laboratory. $\mathrm{S} /$ he reappears only when there are results to communicate.

The researcher does not suffer from this distance during the experimentation phase. Isolation is necessary in order properly to complete any experiments, as well as to protect the results from the community. Contrary to the earlier discussion, sharing results with the community only occurs when they are published officially in a peer- reviewed journal. Confidentiality and competition interfere in the researcher's rapport with the community. Furthermore, the researcher must also demonstrate the scientific consistency and credibility of their work to this same community. Importantly, it is during the final phase of the scientific communication process (the reviewed article) rather than over time that the researcher's relationship with the community is solidified. The open repositories are seen as irrelevant, a 'Napster of science' for the biologists, or as a 'curiosity' for the geologists and chemists. Hyper Article en Ligne (HAL) [8], the French National Open Archive, is almost unknown among this population. This relationship, built upon 'vigilant distance' is translated and deepened through this population's informational practices. These researchers primarily use specialised databases (PubMed [9], ScienceDirect [10], SpringerLink [11] ...). This distance is slightly altered through the consultation of bibliometric databases (Web of Science [12], Scopus [13] or Google Scholar [14]). The search results on these databases are 'filtered' based on the reference's impact on the community (number of citations, source of the citation).

The researcher positions his or her research based on the possible response it will receive within this community. This is even truer for interdisciplinary studies, since one must convince the communities of the different fields upon which the study draws. The most active and experienced researchers are the most expert citation arbitrators. They are also the oldest members of the community. When showing us how they proceeded, it was possible to see how these researchers mobilised their knowledge of research themes and their historicity, as well as their understanding of institutional and individual actors. Pertinent articles are identified based on content, but also on their relationship with the community and its referential framework. Based on these informational, communicational and sociological considerations, the meaning of citations is reclaimed.

With this configuration as its basis, Google is an important source of second-hand information. It is useful when a researcher is beginning a new study and wants to get a sense of its Web presence, or when s/he is preparing a class on a specific subject and wants to find illustrative material (images, multimedia texts). Google is also used to access favourite 
journals or specialised platforms. But scientific publications continue to be crucial. Contrary to what we saw earlier, the social practices of these disciplines prevent researchers from adopting only Google generation practices. The researchers' behaviour and usage continue to be based on the fundamental values that dictate how the field functions.

\section{Convergence and intradisciplinarity}

We have just seen that the type of research and the social representation of the researcher generate different practices. These two elements also act to recalibrate the practices. That said, it is important to underline a convergence among the practices identified in our study. We have interpreted this standardisation as being due to the widespread usage of Google (Googlisation). Our most important finding is the total absence of the concept of a library (in the physical and traditional sense) from the researchers' discourse. As access to electronic platforms has become very common, using libraries is no longer part of the researcher's practices. Library websites were almost never consulted. Researchers preferred to access databases directly or via Google. Some of the researchers we interviewed - the youngest were incapable of identifying who paid the subscription for such and such database (the library, the Centre National de la Recherche Scientifique (CNRS), the laboratory). Furthermore, we observed - and showed in previous studies (Boukacem, 2010) - the widespread adoption of alerts by researchers across disciplines, as well as the dominance of simple searches based on a single keyword. These convergences are symptoms of homogenised infrastructures and technical environments. We focused on the most transversal characteristics and representations in the researchers' discourse in each field. We sought to develop an original way of studying this subject at the preliminary level. Further analyses will allow us to take into account the nuances within each field.

\section{From community to ecosystem and hermeneutics}

Our analysis shows that with an increasing sentiment of belonging and integration into their disciplinary community researchers tend to adopt information and communication habits structured by this same discipline.

In fact, information behaviour seems mainly to be shaped by the researchers' relationship with and representation of their community, in particular by their adhesion to (or rejection of) community values and principles of the disciplinary culture of science. One of the significant results is that some behaviour patterns commonly associated with the phenomenon of the Google generation seem rooted in specific disciplinary practice and the culture of science. In fact, some typical so-called Googling behaviours may have pre-Web origins in disciplinary search patterns. In these cases, technology, the Internet and the Web rather accelerated and intensified existing routines than created new information behaviours.

The Google generation effect does not explain the whole variation of information behaviour. Job status and position affect search logics and patterns. Also, the specific nature of scientific 
enterprise (such as applied science or fundamental research) and the intensity and importance of activity seem related to particular behavioural tendencies and profiles. What we mean is that research and information behaviour are part of a scientific ecosystem wherein the scientific discipline plays a major role. Instead of being amazed by ICT and new ways of searching information, we need to understand underlying functional patterns and the interrelation between information consumption and production, communication and research. Age differences should not be over-interpreted as a generational gap but as a variable of communitarian impact on socialisation and learning processes. Research studies that reveal disciplinary variation in behaviour related to information searching seem to confirm our approach - for instance, disciplinary variation has been found in citing behaviour (Zhang, 2011), citation distribution (Radicchi et al., 2008), the adoption of different Web 2.0 tools (RIN, 2009b), and attitudes to the fundamental functions of scholarly publishing (Mulligan and Mabe, 2011) and open access and deposit behaviour (Fry et al., 2009) - and these behaviours can be impacted by language barriers (Monopoli et al., 2002). This last aspect is of particular interest for studies in France where (non-) usage of digital information may be affected by English reading skills generally higher in younger scientists.

About ten years ago, CIBER performed a cluster analysis on information-seeking data (Nicholas et al., 2004). As a result, they distinguished eight different user groups, such as enthusiastic users ('used the service frequently, accessed a large number of journals, and generally viewed full text articles'), gapfillers ('only accessed a few journals, but did so frequently'), tourists ('used the service, but never viewed a particular journal'), or exploratory users ('infrequent users who seldom accessed full text'). The interesting point is that they included demographic data into the clustering and thus were able to relate multifaceted usage patterns to discipline and academic status. For instance, most enthusiastic users were social scientists while science staff and students predominated in the gapfillers category. This methodology integrates usage assessment, qualitative data collection and complex statistical exploitation. The result seems promising because it allows the researcher to link qualitative studies such as that of Ollé and Borrego (2010) to more concepts of community and discipline. This may be an empirical way to new and realistic ICT hermeneutics of science.

Coming back to our subject, when we highlight the disciplinary differences of informationusage patterns, we do not deny latent age effects and some Google generation-like phenomena. Nevertheless, we think that this effect may be transitional and a kind of collateral effect of emerging ICT in research work. When all Internet users are digital natives, variation related to the hypothetical generation gap will decrease and disappear, and disciplinary differences will (again) become a central factor, reflecting the richness and diversity of fields of science.

\section{Notes}

1. Also called the net generation or generation $\mathrm{Y}$; see overview from Nicholas et al. 
(2011).

2. ICT in urban development, cf. Menou (2010).

3. Researchers of Tomorrow; http://www.efc.co.uk/projects/researchers of tomorrow.jsp

4. We understand disciplines as groupings based on their knowledge structures and reputational concerns (Becher, 1994).

5. http://www.sciencedirect.com/

6. http://www.agence-nationale-recherche.fr

7. E-print archive, covering the fields of physics, mathematics, non-linear science, computer science and quantitative biology; see: http://arxiv.org.

8. http://hal.archives-ouvertes.fr

9. http://www.ncbi.nlm.nih.gov/pubmed/

10. See note 5 .

11. http://www.springerlink.com/

12. http://thomsonreuters.com/products services/science/science products/az/web of science/

13. http://www.scopus.com/home.url

14. http://scholar.google.co.uk/

\section{References}

Becher, T. (1994) 'The significance of disciplinary differences', Studies in Higher Education, 19(2): 151-61.

Boukacem-Zeghmouri, C. (2010) 'Pratiques de consultation des revues électroniques par les enseignants chercheurs: les STM en France', Documentaliste - Sciences de l'Information, 47(2): 4-13.

Connaway, L.S. and Dickey, T.J. (2010) 'The Digital Information Seeker. Report of Findings from Selected OCLC, RIN and JISC user behaviour projects', Tech. rep., JISC OCLC.

Fry, J., Oppenheim, C., Probets, S., Creaser, C., Greenwood, H. and Spezi, V. (2009) 'PEER Behavioural Research: Authors and Users vis-à-vis Journals and Repositories. Baseline Report', Tech. rep., LISU Loughborough University.

Jamali, H.R. and Nicholas, D. (2008) 'Information-seeking behaviour of physicists and astronomers', Aslib Proceedings, 60(5): 444-62.

Jamali, H.R. and Nicholas, D. (2008) 'Intradisciplinary differences in reading behaviour of scientists: case study of physics and astronomy', Electronic Library, 28(1): 54-68.

Jamali, H.R. and Nicholas, D. (2010) 'Interdisciplinarity and the information- seeking behavior of scientists', Information Processing and Management, 46(2): 233-43.

JISC (2009) ‘National E-Book Observatory Project. Key findings and recommendations', Tech. 
rep., JISC.

King, D.W., Tenopir, C., Choemprayong, S. and Wu, L. (2009) 'Scholarly journal informationseeking and reading patterns of faculty at five US universities', Learned Publishing, 22(2): 126-44.

Kurek, K. et al. (2007) 'The research entrepreneur: strategic positioning of the researcher in his societal environment', Science and Public Policy, 34(7): 501-13.

Le Marec, J. (2001) 'L'usage et ses modèles: quelques reflexions méthodologiques', Spirale, 2: 105-22.

Menou, M.J. (2010) 'Information behaviour of the "Google generation" as a factor in sustainability for Mexican cities', Aslib Proceedings, 62(2): 165-74.

Monopoli, M., Nicholas, D., Georgiou, P. and Korfiati, M. (2002) 'A user- oriented evaluation of digital libraries: case study the "electronic journals" service of the library and information service of the University of Patras, Greece', Aslib Proceedings, 54(2): 103-17.

Mulligan, A. and Mabe, M. (2011) 'The effect of the Internet on researcher motivations, behaviour and attitudes', Journal of Documentation, 67(2): 290-311.

Nicholas, D., Huntington, P. and Watkinson, A. (2005) 'Scholarly journal usage: the results of deep log analysis', Journal of Documentation, 61(2): 248-80.

Nicholas, D., Huntington, P. and Jamali, H.R. (2007) 'Diversity in the information seeking behaviour of the virtual scholar: institutional comparisons', Journal of Academic Librarianship, 33(6): 629-38.

Nicholas, D., Huntington, P. and Jamali, H.R. (2008) 'User diversity: as demonstrated by deep log analysis', Electronic Library, 26(1): 21-38.

Nicholas, D., Huntington, P. and Watkinson, A. (2004) 'Re-appraising information seeking behaviour in a digital environment: bouncers, checkers, returnees and the like', Journal of Documentation, 60(1): 24-43.

Nicholas, D., Rowlands, I., Clark, D. and Williams, P. (2010) 'Researchers' e-journal use and information seeking behaviour', Journal of Information Science, 36(4): 494-516.

Nicholas, D., Rowlands, I., Clark, D. and Williams, P. (2011) 'Google Generation II: web behaviour experiments with the BBC', Aslib Proceedings, 63(1): 28-45.

Nicholas, D., Williams, P., Rowlands, I. and Jamali, H.R. (2009) 'Online use and information seeking behaviour: institutional and subject comparisons of UK researchers', Journal of Information Science, 35(6): 660-76.

OCLC (2006) 'College Students' Perceptions of the Libraries and Information Resources: A 
Report to the OCLC Membership, OCLC, Dublin, OH', Tech. rep., OCLC.

Ollé, C. and Borrego, Ã. (2010) 'A qualitative study of the impact of electronic journals on scholarly information behavior', Library and Information Science Research, 32(3): 221-8.

Prensky, M. (2001) 'Digital natives, digital immigrants part 1', On the Horizon - The Strategic Planning Resource for Education Professionals, 9(5): 1-6.

Radicchi, F., Fortunato, S. and Castellano, C. (2008) 'Universality of citation distributions: toward an objective measure of scientific impact', Proceedings of the National Academy of Sciences, 105(45): 17268-72.

RIN (2006) 'Researchers and Discovery Services: Behaviour, Perceptions, Needs', Tech. rep., Research Information Network.

RIN (2009a) 'E-journals: Their Use, Value and Impact', Tech. rep., Research Information Network.

RIN (2009b) 'Communicating knowledge: how and why researchers publish and disseminate their findings', Tech. rep., Research Information Network.

Rowlands, I., Nicholas, D., Williams, P., Huntington, P., Fieldhouse, M., Gunter, B., Withey, R., Jamali, H.R., Dobrowolski, T. and Tenopir, C. (2008) 'The Google generation: the information behaviour of the researcher of the future', Aslib Proceedings, 60(4): 290-310.

Schulmeister, R. (2008) ‘Gibt es eine Net Generation?’, Working Paper. Universität Hamburg, Zentrum für Hochschul- und Weiterbildung. Available online at: http://www.zhw.unihamburg.de/pdfs/Schulmeister_Netzgeneration.pdf.

Tenopir, C., King, D.W., Edwards, S. and Wu, L. (2009) 'Electronic journals and changes in scholarly article seeking and reading patterns', Aslib Proceedings, 61(1): 5-32.

Tenopir, C., Wang, P., Pollard, R., Zhang, Y. and Simmons, B. (2004) 'Use of electronic science journals in the undergraduate curriculum: an observational study', Proceedings of the American Society for Information Science and Technology, 41(1): 64-71.

Williams, P., Nicholas, D. and Rowlands, I. (2010) 'E-journal usage and impact in scholarly research: a review of the literature', New Review of Academic Librarianship, 16(2): 192-207.

Zhang, L. (2011) 'Use of web resources in the journal literature 2001 and 2007: a crossdisciplinary study', College and Research Libraries, 72(2): 167-79. 